\title{
DAVID HUME CONTRA OS CONTRATUALISTAS DE SEU TEMPO
}

\author{
Gabriel Bertin de Almeida* \\ gabrielb@usp.br
}

RESUMO $O$ objetivo do texto é propor uma interpretação da obra de Hume que permita uma outra maneira de refutação ao contratualismo, diversa da refutação "oficial", baseada, aquela interpretação, no conceito de artifício, significativamente diferente do artifício criado pelos contratualistas, oposição esta a que a tradição de comentaristas da filosofia política humeana, de maneira geral, não faz referência, quando se trata da refutação ao contratualismo.

Palavras-Chave David Hume; Contratualismo; Refutação ao Contratualismo; Filosofia Política

ABSTRACT The objective of the text is to propose an interpretation of Hume's works that allows another way of refusing contractualism, different from the "official" refusal, and which is based (the new one) on the concept of artifice, which is extremely different from the artifice created by the contractualists, whose opposition the tradition of commentators of Humean political philosophy, generally, do not refer to, when it is the case of refusing contractualism.

Keywords David Hume; Contractualism; Refutation of Contractualism; Political Philosophy

* Professor da PUC-PR, Campus Londrina. Doutorando em Filosofia pela USP. Artigo recebido em outubro de 2005 e aprovado em abril de 2007.

KRITERION, Belo Horizonte, n 115, Jun/2007, p. 67-87. 


\section{Introdução}

No ensaio chamado Da superstição e do entusiasmo, Hume descreve o que chama de duas "formas corruptas da verdadeira religião" (2002, p. 75), ambas igualmente perniciosas, embora contrárias. A primeira delas, a superstição, é um estado de espírito sujeito a temores e apreensões incompreensíveis, atribuídos a agentes desconhecidos. São suas fontes a fraqueza, o medo, a melancolia, juntamente com a ignorância. Contra aqueles temores invisíveis são utilizados métodos igualmente incompreensíveis, "como cerimônias, proibições, mortificações, sacrifícios, oferendas e toda a espécie de práticas, por mais absurdas e frívolas que sejam, capazes de serem aconselhadas pela loucura ou pela patifaria a uma cega e atemorizada credulidade" (Hume, 2002, p. 75). A segunda, o entusiasmo, é um estado de incompreensível exaltação e presunção. Suas fontes são o sucesso, a prosperidade, a abundância de saúde, o caráter ousado e confiante, junto com a esperança, com o orgulho, com a presunção e, também, com a ignorância. Essa situação provoca uma série de arrebatamentos, de vôos da fantasia, muito além do alcance de nossas faculdades normais (Hume, 2002, p.76).

Assim, a superstição torna mansos e abjetos os homens, enquanto o entusiasmo é uma enfermidade própria dos temperamentos ambiciosos e ousados. Hume passa então a divagar sobre os efeitos desses males sobre o governo e a sociedade, dizendo que, em relação ao primeiro, o homem se vê "em cores tão desprezíveis que ele aparece a seus próprios olhos como indigno de se aproximar da divina presença, e naturalmente recorre a qualquer outra pessoa (...)" (Hume, 2002, p. 76). Quanto ao segundo, o orgulho e a confiança fazem com que o homem considere-se "suficientemente qualificado para se aproximar da Divindade sem qualquer mediador humano" (Hume, 2002, p. 76).

Provocativamente, diz Hume que as teorias políticas de sua época teriam fortes vínculos com essas duas falsas religiões, e sua tarefa é demonstrar que são filosoficamente mal concebidas, empiricamente insustentáveis e, se levadas a seus limites, politicamente perigosas. ${ }^{1}$ Vê-se, então, que seu objetivo é demonstrar os equívocos dessas duas maneiras de se pensar a política. Os partidos Whig e Tory, que disputavam o poder na Inglaterra do século XVIII e que, em suas formas mais radicais, teriam raízes no entusiasmo e na superstição, enquadram-se na crítica humeana. 
Em outro ensaio, mais conhecido (Do Contrato original), Hume assim comenta as características básicas dos dois partidos políticos de maior influência em seu tempo:

Um dos partidos, filiando o governo à Divindade, procura torná-lo tão sagrado e inviolável que constitui pouco menos que um sacrilégio, por mais tirânico que seja, feri-lo ou violá-lo no menor aspecto. O outro partido, fazendo o governo depender inteiramente do consentimento do povo, supõe a existência de uma espécie de contrato original, mediante o qual os súditos se reservaram tacitamente o direito de resistir ao seu soberano, de cada vez que se sentirem prejudicados por aquela mesma autoridade que a ele, para certos fins, voluntariamente confiaram (2002, p. 399).

Algumas vertentes do partido Tory, defensor de irrestrita obediência passiva, em que pese ter maior simpatia de Hume, ${ }^{2}$ representam a superstição, pois o supersticioso aceita a existência de poderes inerentes à natureza das coisas, inclusive a existência de uma hierarquia natural, que o faz aceitar ser o poder monárquico a única forma de autoridade derivada do direito divino. Algumas facções do partido Whig representam o entusiasmo, personificado pelo contratualismo. Para os entusiastas, o autogoverno é o único que possui legitimidade. Assim, defendem teorias contratualistas porque dependem do consentimento e favorecem a proteção dos direitos e liberdades individuais, ${ }^{3}$ em maior ou menor grau.

É importante notar que Hume demonstra grande preocupação em refutar os entusiastas defensores do contratualismo. Quanto aos supersticiosos tories, dedica menor número de linhas. Duncan Forbes diz que a teoria do contrato era a que mais incomodava o criticismo de Hume, pois a crença no direito divino e na obediência passiva tinha perdido espaço em uma situação de maior progresso cultural e de liberdades ${ }^{4}$. Era a teoria do contrato, portanto, como diz o próprio Hume no Tratado, o "sistema político da moda" (TNH, III, II, VII, p. 347). Nesse contexto, o presente artigo tem por objeto a crítica humeana ao contratualismo de seu tempo.

Porém, é importante desde logo fazer referência à refutação expressa de Hume, a que chamarei de "oficial", em que estão presentes as discussões a respeito do papel do consentimento, da existência de estado de natureza e do pacto expresso ou tácito, da obrigação decorrente das promessas, da origem do governo e da obediência. Não é dessa refutação que trata o presente texto. 
Nosso objetivo é estudar o conceito de artifício (e de justiça) em Hume, significativamente diferente do artifício criado pelos contratualistas, distinção esta a que a tradição de comentaristas da filosofia política humeana de maneira geral não faz referência, quando se trata da refutação ao contratualismo. Assim, acreditamos ser possível propor uma outra maneira de refutar o contratualismo, além daquela feita expressamente por Hume.

\section{A justiça no Tratado: uma meia-virtude ainda é virtude?}

Vejamos primeiro o que consta do Tratado, sua primeira obra. Estabelecido que o homem é um "ser familiar", porque nasce, no mínimo, em uma sociedade familiar (que, por sua vez, decorre do instinto sexual), Hume passa a afirmar que a natureza humana possui, entre outras, duas paixões, o egoísmo e a generosidade limitada, ${ }^{5}$ que podem impossibilitar a convivência entre os homens. E essa situação de parcialidade, em que a generosidade é limitada porque diz respeito às pessoas que nos são próximas, é um perigo para a continuação da sociedade, devido à fragilidade da proteção dos bens de cada um.

Assim, a primeira idéia de moralidade é parcial na medida em que é reprovável o ato de quem negligencia sua família em favor de um estranho. Por isso, essa idéia primitiva de moralidade, ao invés de remediar a parcialidade de nosso espírito, apenas com ele se conforma. ${ }^{6}$ Logo, a solução para a parcialidade de nosso espírito não é natural, mas artificial. Como os homens nascem pelo menos em uma sociedade familiar e são nela educados, desde logo tomam consciência, através da ação do hábito, dos benefícios da vida em grupo e da conversação e, para mantê-la, devem dar estabilidade às posses. O artifício que proporciona essa estabilidade tem, diz Hume, origem na convenção, que, por sua vez, deriva da inventividade dos homens e da ação do hábito. E essa convenção refere-se às regras de justiça, que provêm de um interesse comum e implicam a definição de regras de conduta, interesse esse que surge quando é mutuamente formulado e conhecido, produzindo um comportamento que lhe corresponda.

Pelo exposto, vê-se que para a explicação da vida em família basta o instinto sexual. Para a explicação da vida em sociedade é necessária, ainda, a força do hábito, a existência dos fatores externos mencionados, relativos à 
raridade dos bens cuja posse é pretendida e, também, um artifício: a convenção que determina as regras de justiça.

A justiça é então o que Hume chama de "virtude artificial", porque surge da adoção de um sistema de condutas. Ela não é como a beneficência e a moderação, por exemplo, virtudes naturais que independem de qualquer artifício. Só depois de instituída é que a justiça passa a ser "naturalmente" aprovada. ${ }^{7}$ Assim, uma das diferenças entre virtude natural e artificial é que o bem resultante da primeira surge de atos isolados, enquanto que um ato de justiça pode ser contrário ao bem do agente ou mesmo ao bem público se isoladamente considerado; "o que é vantajoso é apenas a concorrência de todos os homens em um esquema ou sistema geral de ações" (THN, III, III, I, p. 370). Assim, a justiça depende da prática social. Daí a proximidade entre a explicação do artifício e a formação do vínculo social.

É interessante notar que atos de justiça podem ser contrários ao interesse das pessoas nele envolvidas ou mesmo ao interesse público. E isso torna mais difícil verificar porque devemos continuar a aprová-los e praticá-los. Para discutir o tema, vejamos a seguinte hipótese: se empresto dinheiro de alguém, porque o devolver? Um motivo poderia ser o interesse próprio em manter uma boa reputação para, por exemplo, ter a possibilidade de obter outros empréstimos no futuro. Hume de fato aponta a preocupação pessoal com a reputação como um meio de fortalecimento dos atos de justiça. ${ }^{8}$ Mas, sem essa preocupação, seja porque motivo for não a tenhamos, não o devolveríamos. Nessa hipótese, o "mais promissor candidato a motivo da justiça é a preocupação com o interesse público (...), mas mesmo esse não pode ser visto, sem complicações, como operativo em cada caso particular" (Stroud, 1995, p. 200). Isso porque o próprio interesse público pode sofrer em razão de um ato justo. É o que acontece, diz Hume, quando um homem de mérito devolve uma grande fortuna para um fanático sedicioso. ${ }^{9}$ Nesse caso, o homem agiu de maneira justa, mas o interesse público é prejudicado. Logo, esse interesse não explica sempre a devolução do dinheiro. De qualquer modo, Hume diz que ainda assim "esse mal momentâneo é amplamente compensado pela contínua progressão da regra e pela paz e ordem que se estabelece na sociedade" (THN, III, II, II, p. 319). Portanto, a instituição da justiça traz efeitos colaterais. Como diz Stroud, esses efeitos são como as dores de uma cirurgia: "Apesar de inevitável, (...) ainda podemos ser motivados a submetermo-nos à cirurgia 
porque acreditamos que os benefícios compensam a dor"(1995, p. 206). Essas considerações ilustram a dependência do conceito de justiça em relação a uma prática social e, ainda, o fato de que atos considerados isoladamente podem parecer absurdos e, mesmo assim, justos.

Continuemos então a buscar o motivo de agirmos segundo as convenções humanas quanto às regras de justiça, decorrentes dos inconvenientes originados da oposição entre alguns atributos de nosso espírito e da situação dos objetos exteriores. Como a justiça é, para Hume, uma virtude, e como tal tem origem nas paixões, é certo que ela não deriva de uma relação de idéias, mas se funda nas impressões. Além disso, os homens usualmente não procuram o interesse público de maneira natural; pelo contrário, muitas vezes buscam seus próprios interesses, particulares, sem as precauções devidas. No entanto, o interesse e, conseqüientemente, os prazeres visados, conforme a teoria humeana das paixões, sempre estão presentes nas ações humanas, de forma que a justiça deve neles se fundar de algum modo.

O primeiro motivo da instituição da justiça é o interesse próprio, representado pelo desejo de fruir determinado objeto, e pela benevolência limitada aos nossos familiares e amigos. Por isso, pode-se dizer que o interesse próprio fundamenta o que Hume chama no Tratado de obrigação natural de justiça. ${ }^{10}$ Mas a procura da satisfação desse interesse próprio muitas vezes impede a convivência pacífica. É que nos homens não há a referida inclinação natural para a defesa do interesse público, mas somente do interesse particular. Como a procura deste último instauraria violência generalizada, devem ser "artificialmente" instituídas as regras de justiça. Por isso, a teoria humeana das paixões afirma que a paixão dominante é o interesse próprio ou particular, movido pelo desejo de algo que proporcione prazer imediato e, sobretudo, futuro. Para que houvesse uma defesa natural do interesse público seria necessária uma nova paixão, pelo bem público, o que não se dá, segundo Hume, com frequiência, "pois os homens têm por característica preferir um proveito imediato a algo mais distante" (THN, III, II, II, p. 312). Assim, o interesse público exige uma análise mais atenta, pois não é a própria estabilidade da sociedade que é prazerosa e auto-suficiente. O que é objeto da paixão são as conseqüencias dessa estabilidade, ou seja, a situação do grupo social em que se torne possível a fruição tranqüila e segura dos objetos que produzem prazer. 
É importante notar que a observância das regras de justiça nas sociedades familiares é mais forte do que nas sociedades mais numerosas. ${ }^{11}$ Depois de verificarem que a sociedade é necessária para a satisfação de suas paixões, os homens passam naturalmente a respeitar determinadas regras. No entanto, nas sociedades mais numerosas os prejuízos causados pelos atos contrários à convenção, isto é, às regras de justiça, são mais dificilmente verificados, pois "se perdem em um campo de experiência mais complexo" (Monteiro, 1975, p. 67). Por isso, o interesse no respeito às regras de justiça é menor. Assim, inicialmente, a convenção quanto às regras de justiça é conveniente para todos, a fim de que possam viver em sociedade e colher os benefícios que dela decorrem. Quando os prejuízos causados pela transgressão das regras que determinam a manutenção das posses tornam-se mais difíceis de ser verificados, o interesse perde sua força como paixão determinante da justiça. Como toda ação é motivada por uma impressão, perdendo força essa impressão, diminui-se sua qualidade de crença, possibilitando-se o aparecimento de outros interesses e sentimentos, mais próximos e vivos, que constituem os móbeis da ação, contrários às regras de justiça. Assim, nas sociedades mais numerosas, podese muitas vezes perder de vista o interesse que nos faz seguir tais regras.

Por isso, a simpatia, que hoje chamaríamos mais propriamente de empatia, possibilita o sentimento de desagrado em situações que não afetam o interesse pessoal. Assim, "uma simpatia pelo interesse público é a fonte da aprovação moral que acompanha essa virtude" (THN, III, II, II, p. 321, grifos no original). No entanto, a simpatia "é fraca demais para controlar nossas paixões; mas tem força suficiente para influenciar nosso gosto, e para nos dar os sentimentos de aprovação ou de condenação" (THN, III, II, II, p. 321). A passagem de John Rawls, em Uma teoria da justiça, abaixo transcrita, serve para ilustrar o que é essa simpatia pelo interesse público, chamada de aprovação:

Para simplificar podemos supor, como faz Hume algumas vezes, que a aprovação é um tipo específico de prazer que se origina mais ou menos intensamente diante da contemplação do funcionamento das instituições e de suas conseqüências para a felicidade daqueles que nelas estão engajados. Esse prazer especial é o resultado da compreensão da situação dos outros. Na explicação de Hume, ele é literalmente uma reprodução, em nossa experiência, das satisfações que reconhecemos que os outros sentem (Rawls, 1999, p. 162).

Portanto, em resumo, há uma obrigação natural de justiça, através da qual o homem age, em geral, de acordo com seus interesses particulares (egoísmo) 
e segundo interesses de pessoas que lhe são próximas (benevolência parcial). Esse interesse evita que se pratiquem atos lesivos ao pequeno grupo social e ao próprio indivíduo. Além desse grupo, como não há na natureza humana interesse público ou sentimento de humanidade que sirva de móbil para a ação, a existência das sociedades mais numerosas estaria comprometida. Por isso, dependem do artifício, isto é, da convenção humana sobre as regras de justiça.

Essa tática ou artifício que inventamos completa os chamados "dois estágios de desenvolvimento" (Rawls, 2000, p. 66): o primeiro, referido acima, da obrigação natural, suficiente em uma sociedade familiar, e o da obrigação moral, necessário em uma sociedade mais numerosa. Nesse sistema de justiça, que surge porque não somos benevolentes o suficiente para abstermo-nos das posses dos outros, haveria uma "alteração da direção" de nosso interesse ${ }^{12}$ (enlightened self-interest). Abstemo-nos de atos lesivos a outros porque isso nos favorece na medida em que possibilita a vida em sociedade e a manutenção de nossos bens. Forbes diz que a "justiça e a sociedade humana foram possíveis porque a paixão socialmente destrutiva foi redirecionada pelo entendimento" (1975, p. 69). Assim, o mesmo interesse que põe em risco a sociedade serve, com o auxílio do entendimento, à sua preservação.

Portanto, a distinção entre obrigação natural e moral serve para opor a primeira obrigação, que é natural porque independe de que o sujeito tenha consciência dela, à segunda, que é moral porque pressupõe que o sujeito adquiriu essa consciência, o que Hume esforça-se para explicar. João Paulo Monteiro, em obra recente, esclarece essa distinção:

Tudo parece indicar que esse segundo tipo de obrigação recebe este adjetivo, "moral", devido a sua ligação com a "moralidade", mas é importante ver que este é mais um caso em que as aparências iludem. No vocabulário filosófico humeano, como aliás na língua inglesa falada e escrita no século XVIII, quando "moral" se opõe a "natural", como no presente caso, o que é natural é-o independentemente de qualquer passagem pela mente do sujeito, e o que é moral é assim adjetivado apenas porque depende de algo mental (...). Cada um de nós tem a obrigação natural de cuidar do que é de seu interesse, quer saiba disso quer não - mas só se pode ter uma obrigação moral quando se adquire consciência dessa mesma obrigação (2003, p. 166-167, grifos no original).

Quando Hume diz que agimos em conformidade a um sistema geral de ações em razão de nossa simpatia pelos "interesses da sociedade" (TNH, III, II, II, p. 321), que é a fonte da aprovação moral da justiça, pode-se notar 
uma impropriedade. A simpatia, segundo o conceito humeano, bem descrito por Rawls na passagem anteriormente transcrita, diz respeito a ações ou sentimentos de outras pessoas, e não diretamente ao interesse público, ou a qualquer outra idéia. "A simpatia consiste na capacidade enfática de detectar o estado mental de outras pessoas e, como resultado, de ter uma experiência similar àquela da pessoa em consideração" (Baillie, 2000, p. 56, grifos no original). Portanto, como se trata de detectar estados mentais, só pode haver simpatia entre pessoas, e não também entre pessoas e idéias, ou uma simpatia "pelo interesse público". Esse estado mental é, mais precisamente, uma operação da imaginação que pressupõe uma primeira impressão, relacionada à experiência que temos da observação da situação de outras pessoas, de dor ou de prazer, que se liga a uma idéia de uma impressão anterior, que, por sua vez, em razão de sua vivacidade, é transformada em uma outra e nova impressão, de prazer e desprazer, aprovação ou desaprovação, correspondente àquela primeira impressão. Em razão desse mecanismo, Rawls diz que a simpatia age como uma infecção, não porque discerne os estados mentais dos outros, mas porque faz inferências em razão de seus comportamentos e ações externas. ${ }^{13}$

Baillie diz que a "simpatia não é algo que 'fazemos' intencionalmente, mas que toma lugar involuntariamente em um nível de irreflexão natural. Não é um produto da razão (...), nem a manipulação deliberada da imaginação para colocar uma pessoa no lugar da outra" (2000, p. 57). Hume fala em "princípio da simpatia ou comunicação" (TNH, II, III, VII, p. 273), isto é, quer dizer que a simpatia não é uma paixão ela própria, como a piedade ou a compaixão, por exemplo, mas sim um sentimento com características específicas, de conhecimento e absorção de sentimentos de outras pessoas, ou seja, um canal de comunicação de estados mentais, e não propriamente uma paixão: "Não é ela [a simpatia] mesma uma paixão, pois não tem qualidade própria. Então, como mencionado acima, não pode ser confundida com piedade" (Baillie, 2000, p. 59). ${ }^{14}$ Assim, não é uma paixão benevolente que nos move, pois não há paixão pelo bem dos outros, suficiente para mover-nos. Em outra passagem, Hume diz:

Suponhamos um homem que pratica muitas boas ações; alivia os sofredores, reconforta os aflitos e leva sua bondade até os mais desconhecidos. Nenhum caráter poderia ser mais amável e virtuoso. Vemos essas ações como provas de um grande sentimento de humanidade. Esse sentimento de humanidade confere um mérito às

13 RAWLS, 2000, p. 86. No Tratado, encontramos o seguinte: "Nenhuma paixão sentida por outra pessoa se descobre imediatamente ao espírito" (TNH, III, III, I, p. 368).

14 No mesmo sentido: STROUD, 1995, p. 197. 
ações. O respeito pelo mérito é, portanto, uma consideração secundária, derivada do princípio antecedente do sentimento de humanidade, que é meritório e louvável (THN, III, II, I, p. 308).

Segundo essa passagem, o sentimento de humanidade (humanity - mais utilizada na segunda Investigação), conceito que às vezes Hume indica ser similar à simpatia "pelo interesse público", poderia ser visto como móbil da ação justa. No entanto, Hume afirma em várias passagens do Tratado que esse tipo de sentimento não é forte o suficiente para mover-nos: "Em geral, pode-se afirmar que não há na mente dos homens uma paixão como o amor ao gênero humano, concebida meramente enquanto tal, independentemente de qualidades pessoais, de favores ou de uma relação da outra pessoa conosco" (THN, III, II, I, p. 309); ou: "Portanto, se a benevolência pública ou uma consideração pelos interesses da humanidade não pode ser o motivo original da justiça, muito menos a benevolência privada, ou seja, uma consideração pelos interesses do outro" (THN, III, II, I, p. 310, grifos no original).

Enfim, segundo se depreende da leitura do Tratado, a virtude da justiça tem origem, em última análise, em nossos interesses privados (motivo: egoísmo e benevolência limitada), sendo o artifício um meio de assegurá-los, ${ }^{15} \mathrm{com}$ o fim de manter a estabilidade das posses, o que acaba coincidindo com o interesse público, porque promove a convivência pacífica.

Vê-se, assim, que a teoria moral de Hume é uma teoria dos sentimentos morais e, ao mesmo tempo, uma teoria das virtudes, ${ }^{16}$ pois há, visivelmente, uma diferença de pontos de vista: o do agente e o do observador. A virtude é encontrada no agente; o sentimento moral no observador. Embora exista uma diferença de pontos de vista, é evidente que o agente pode ser seu próprio observador. De qualquer forma, a justiça, considerando-se o ponto de vista do agente, deriva do interesse pessoal e da benevolência limitada. Do ponto de vista do observador que aprova o ato, é "virtude", porque, via simpatia, identifica um pretenso sentimento moralmente louvável (sentimento de humanidade ou de preocupação com os demais) em um terceiro. Mas essa identificação dáse em razão dos efeitos do ato (sign), e não do motivo. Assim, agimos de acordo com nossos próprios interesses; quando esses interesses coincidem com o bem público, nossa ação é "virtuosa", porque quem contempla seus efeitos assim a vê. A utilidade pública é só um efeito da ação observada, mas

15 "O remédio, portanto, não vem da natureza, mas do artifício; ou, mais corretamente falando, a natureza fornece, no juízo e no entendimento, um remédio para o que há de irregular e inconveninente nos afetos" (THN, III, II, II, p. 314, grifo no original).

16 ARAÚJO, 1996, p. 147. 
parece que é um desígnio compartilhado. ${ }^{17}$ Como esclarece Cícero Araújo, "este fato apenas mostra que o sentimento do observador e a virtude do agente são interdependentes, e não que são idênticos" (1996, p. 148). O problema é que, sendo assim, Hume não pode afirmar que os motivos dos atos de justiça são virtuosos em um sentido forte; logo, não pode afirmar que a justiça é uma virtude (artificial).

Vista por esse ângulo, a justiça passaria a ser uma virtude menos nobre, ou equiparada a algumas das virtudes naturais, porque derivada do interesse próprio, e não de sentimentos distantes da auto-satisfação. Somente quem observa a ação, como sinal de um motivo, supõe, em razão dessa coincidência com o bem comum, que esse motivo não é auto-interessado, embora de fato seja. São moralmente bons ou maus apenas os sentimentos em geral, sem referência a nosso interesse particular. ${ }^{18}$ Hume diferencia sentimentos interessados de sentimentos morais. Os primeiros, segundo o texto do Tratado, são os que determinam a ação. Portanto, a justiça, assim considerada, perderia sua característica mais elementar: seu caráter de virtude. A obrigação de agirmos racionalmente em nosso próprio interesse não pode ser considerada uma virtude. Não em Hume, ou no século XVIII em geral. A noção de "virtude intelectual", diferente da artificial, tomou lugar mais recentemente. A justiça de que ora tratamos só faz sentido como virtude se for respeitada em razão de uma obrigação independente do interesse pessoal.

Vale ressaltar que Hume afirma existir qualidades que constituem uma virtude e ao mesmo tempo dizem respeito a ações interessadas, tais como o engenho (industry), a perseverança, a paciência, entre outras. Porém, essa ambigüidade da teoria não anula passagens mais significativas e enfáticas, como as mencionadas anteriormente, que diz serem "moralmente bons ou maus apenas os sentimentos em geral, sem referência a nosso interesse particular". Ou ainda: "Portanto, se a benevolência pública ou uma consideração pelos interesses da humanidade não pode ser o motivo original da justiça, muito menos a benevolência privada, ou seja, uma consideração pelos interesses do outro".

Portanto, agimos em benefício do bem público por dever, isto é, em acordo a um senso de moralidade, o que não constitui para Hume motivo do ato justo. Isso porque o observador que aprova o comportamento justo como se derivasse de um motivo louvável, ao perceber que lhe falta o mesmo motivo, sente-se portador de um déficit moral, desaprovando-se a si próprio. 
Assim, a internalização de uma "vontade social” (Haakonsen, 1993, p. 191) supriria, via senso de moralidade, o motivo faltante, corrigindo nosso caráter. Mas o motivo diverso desse senso continua ausente, o que expõe uma falha grave na teoria humeana, conforme exposta no Tratado. Assim, embora consiga explicar como anexamos a idéia de justiça, ou de um senso de justiça, o problema referente ao motivo permanece.

Rawls interpreta esse problema de maneira bastante original. Inicialmente transcreve a famosa passagem do Tratado sobre o motivo da ação virtuosa e seu distanciamento do senso de moralidade ("Pode-se estabelecer como máxima indubitável que nenhuma ação pode ser virtuosa ou moralmente boa, se não houver na natureza humana algum motivo que a produza, distinto do senso de moralidade" - TNH, III, II, I, p. 308, grifos no original), dizendo que é difícil de ser interpretada. ${ }^{19}$ Afirma que os parágrafos que sucedem a passagem transcrita a contrariam, pois dizem que, quando somos educados segundo as práticas de uma sociedade civilizada, podemos devolver uma soma de dinheiro em razão de um senso de moralidade. Por isso, os itálicos (passagem anterior, entre parênteses) de Hume referir-se-iam apenas à origem da convenção sobre as regras de justiça, e não à sua continuação. Originariamente, agimos por motivos diferentes do senso de moralidade (egoísmo e benevolência limitada); posteriormente, contrariando Hume, Rawls diz que o motivo é o senso de moralidade.

Para justificar seu entendimento, supõe Rawls que, com relação ao homem em uma "sociedade civilizada", Hume teria dito o seguinte: "Pode-se estabelecer como máxima indubitável que nenhuma ação pode ser virtuosa ou moralmente boa, se não houver na natureza humana algum motivo que a produza, distinto de um motivo sancionado por um comando divino." Assim, Hume distinguir-se-ia de outros expoentes de teorias do direito natural, como os contratualistas Grotius, Pufendorf e Locke, para quem a obrigação moral depende de uma lei de natureza de origem divina, que impõe sua observância não porque são boas para a sociedade, mas porque, antes disso, derivam de Deus. Para Hume, é a utilidade dessas regras, somada a um mecanismo inato, que faz com que internalizemos uma prática social de respeito a elas, e não um comando superior.

A interpretação de Rawls, além de flexibilizar exageradamente o texto do Tratado, não exclui o problema de que a virtude continua tendo um motivo de origem duvidosa (o que ele não procura excluir), pois, do ponto de vista 
do observador, o julgamento das pessoas depende de dois fatos: primeiro, de que a pessoa dotada de um bom motivo tenha êxito no resultado de sua ação, pois só temos acesso aos sinais dela, e, em segundo lugar e inversamente, se houver êxito, de que os sinais derivem de fato de um bom motivo, o que não podemos afirmar. Enfim, a justiça continua uma meia-virtude.

Stroud, por sua vez, diz que a justiça não pode ser considerada uma virtude de segunda classe, pois embora as regras de justiça sejam artificiais, ou fruto da convenção, a aprovação que damos a elas é natural. ${ }^{20}$ Em outras palavras, do ponto de vista do observador, adquirimos o sentido da moralidade de maneira natural, através da simpatia. Insisto, porém, que o problema permanece, pois a naturalidade do mecanismo de aquisição do senso de justiça não determina o caráter virtuoso do motivo da ação. Mas talvez seja possível, através da leitura da segunda Investigação, esclarecê-lo, dando uma outra interpretação ao conceito de artifício, apta não só a diferenciá-lo, com maior facilidade, do conceito dado pelos contratualistas (o que evidentemente já é possível pelo texto do Tratado), mas, sobretudo, apta a melhor refutar as teses do contrato.

\section{A justiça na segunda Investigação: uma virtude inteira}

É bastante conhecida a eloqüente advertência que precede as Investigações, renegando o Tratado e informando ter corrigido algumas negligências que lá existiam. Uma dessas negligências corrigidas diz respeito ao papel da simpatia, que "talvez Hume tenha sentido ter levado muito longe" (Rawls, 2000, p. 102). Por isso, algumas modificações eram necessárias. Porém, apesar de Hume ter feito correções em seus novos textos, a interpretação padrão de sua teoria moral continua sendo aquela que vimos anteriormente, que afirma ser a justiça uma virtude artificial baseada também no interesse próprio de longo prazo, que acreditamos ter suporte mais arraigado no Tratado. Nesse sentido são os comentários de Forbes, Stroud e Mackie. ${ }^{21}$ Acredito, como mencionado, ser possível dar uma outra interpretação ao tema, para, entre outros motivos, expostos a seguir, atender ao reclame do próprio Hume, contido na Advertência anteriormente transcrita.

Hume passa, na segunda Investigação, a utilizar mais o conceito de sentimento de humanidade e menos o de simpatia. De outro modo, elimina as referências à distinção entre obrigação natural e moral de justiça. Vejamos as conseqüências disso. 
Hume diz que não há qualidades que mereçam mais nossa aprovação do que a "beneficência e a humanidade, a amizade e a gratidão, a afeição natural e o espírito público, e tudo o que procede de uma terna simpatia pelos demais e de uma generosa preocupação pelo nosso grupo e espécie" (EPM, II, I, p. 79). Portanto, a virtude afasta-se do interesse próprio, aproximando-se das ações desinteressadas e das que visam o interesse público. Ressalte-se que também aqui podemos encontrar a mesma ambigüidade encontrada no Tratado, já que Hume divide as qualidades mentais de um caráter virtuoso em quatro (a divisão entre virtudes naturais e artificiais perde espaço): as socialmente úteis, as úteis para o próprio agente, as imediatamente agradáveis aos outros e as imediatamente agradáveis ao próprio agente. Desse quadro também extraímos várias "virtudes interessadas". Nem por isso, porém, deixa de existir uma forte sugestão de classificação das virtudes como mais ou menos nobres, sendo que uma virtude social, como é o caso da justiça, continua sendo mais importante, justamente porque é desinteressada.

Diz também Hume que o mérito da virtude da justiça deve-se aos benefícios sociais que dela decorrem, ou seja, à sua utilidade pública. ${ }^{22}$ Repetindo o que afirmou no Tratado, menciona que em situações de extrema abundância ou penúria, no que se refere aos bens, ou de extrema humanidade ou malícia, no que se refere ao caráter, a justiça seria desnecessária. ${ }^{23}$ Nossa condição seria a de um meio termo entre esses extremos, pois somos "naturalmente parciais para conosco mesmos e nossos amigos, mas somos capazes de compreender a vantagem resultante de uma conduta mais equânime" (EPM, III, I, p. 96). Ou seja, somos parciais, mais equânimes.

Mas o que significa ser parcial e equânime ao mesmo tempo? Significa mover-se por egoísmo e humanidade ao mesmo tempo? O sentimento de humanidade passaria a ser também móbil decisivo da ação? No Tratado, como foi visto, o sentimento que nos movia era, predominantemente, o interesse privado, dirigido pelo entendimento e transformado em senso de moralidade, apesar de algumas passagens sugerirem o contrário. Porém, na segunda Investigação, entre várias outras passagens que elastecem o papel do sentimento de humanidade, Hume afirma que a "mais óbvia objeção à hipótese egoísta é que, dado que é contrária ao sentimento comum e a nossas idéias mais imparciais, constitui um paradoxo extraordinário cujo estabelecimento demanda um imenso contorcionismo filosófico" (EPM, Apêndice II, p. 166). 
Em seguida, diz que é evidente que existem no homem disposições como a benevolência, a generosidade, a amizade, a compaixão, entre outras. ${ }^{24}$

Ora, Hume está, então, corrigindo uma negligência do Tratado, presente na passagem referida anteriormente, em que afirmou ser o sentimento de humanidade o interesse próprio modificado, ${ }^{25}$ isto é, alterado pelas circunstâncias exteriores e pela ação do entendimento.

Essa correção é mais evidente em um dos apêndices da segunda Investigação, em que menciona dois posicionamentos filosóficos comuns sobre o tema: ${ }^{26}$ o primeiro diz que toda benevolência é mera hipocrisia, que sempre buscamos nossos interesses e que nossas demonstrações de amizade, espírito público e fidelidade são apenas maquinações; o segundo diz que, seja qual for o afeto que alguém possa sentir ou imaginar que sinta pelos outros, nenhuma paixão é desinteressada. Tudo é, então, modificação do amor a si mesmo. Nossa imaginação e a reflexão fazem com que nos imaginemos isentos de considerações egoístas. Note-se que, como visto, a posição de Hume no Tratado aproximava-se, quanto à virtude da justiça, desta última concepção, já que o motivo de uma ação justa é o interesse próprio dirigido pelo entendimento. Ao final, diz, porém, que ambas são equivocadas. Agora, então, sua teoria tem os seguintes contornos:

Se é fato que o homem pode sentir as alegrias e os infortúnios dos outros e assim considerar o bem estar deles, o que não é simplesmente uma função do interesse próprio, então esse é um importante fato para a filosofia moral, e especialmente para uma filosofia moral, como a de Hume, que é baseada em uma explicação da natureza do homem. (Esse é apenas um dos temas em que a atitude otimista do Tratado não sobreviveu muito após sua publicação; e as duas Investigações são muito mais modestas em suas afirmações) (Kemp, 1970, p. 36).

Revista a negligência, vê-se que o sentimento de humanidade é algo tão natural quanto nossos instintos egoístas, sendo que a virtude da justiça não é mais apenas uma obrigação de agirmos em nosso próprio interesse. $\mathrm{O}$ sentimento de humanidade é também um princípio geral da natureza humana, assim como o egoísmo e a benevolência limitada, que não pode ou não precisa ter sua causa descoberta:

Quando escreveu a Investigação, Hume tratou a existência da simpatia (ou humanidade, como agora prefere chamá-la) como um fato básico e inexplicado. 
"É desnecessário prosseguir nossa pesquisa para perguntarmos porque temos sentimento de humanidade ou amizade por outros. É suficiente que isso tenha sido experimentado como um princípio da natureza humana. Devemos parar em algum lugar nossa investigação das causas; e existem, em toda ciência, alguns princípios gerais além dos quais não esperamos encontrar nenhum princípio mais geral" (EPM V, II 47 ni 219ni) (Kemp, 1970, p. 36).

Vejamos outra passagem em que Hume enfatiza a função do sentimento de humanidade para influenciar nossa ação e nossa aprovação dos atos dos outros:

Levamos com certeza em consideração a felicidade e a desgraça dos outros ao pesar os diversos motivos para uma ação, e inclinamo-nos para a primeira sempre que considerações de caráter privado não nos levem a procurar nossa própria promoção ou vantagem à custa do prejuízo de nossos semelhantes. E se os princípios de humanidade são capazes, em muitas ocasiões, de influenciar nossas ações, eles devem ter em todos os momentos alguma autoridade sobre nossos sentimentos, fazendo-nos aprovar em geral o que é útil para a sociedade e censurar o que é perigoso ou nocivo. Os graus desses sentimentos podem ser assunto de controvérsia, mas não há como negar que a realidade de sua existência deve ser admitida em qualquer sistema ou teoria (EPM, V, II, p. 114, grifo no original).

Se a teoria for interpretada desse modo, a distinção entre obrigação natural e moral de justiça, conforme explicada no Tratado, deixa de existir, pois o que determina a ação e a aprovação é esse mesmo sentimento de humanidade. Para explicar a justiça como uma "verdadeira" virtude, fundada em um sentimento desse tipo, era necessário, então, livrar-se de algumas afirmações feitas no Tratado, sobre a dicotomia do conceito de justiça e sobre a impotência do sentimento de humanidade como móbil da ação virtuosa. Enfim, essa sensível reformulação da teoria pode ser considerada como o reconhecimento de uma das negligências contidas no Tratado, para admitir, na segunda Investigação, a existência do sentimento de humanidade também como móbil da ação e, ainda, para reconhecer a impossibilidade de atribuir-lhe uma causa, motivo pelo qual foi erigido à condição de princípio da natureza humana.

Se o sentimento de humanidade não fosse móbil possível da ação, não haveria propriamente ação virtuosa, naquele sentido forte já mencionado (ação desinteressada). Nesse caso, todas as ações seriam interessadas. Como a moralidade da ação é medida por seu motivo, a aprovação desse tipo de ação seria autocontraditória, tendo lugar apenas como apreciação equivocada de seus sinais (signs).

Tais conclusões, porém, poderiam sugerir que a justiça teria passado a ser uma virtude natural, pois a ênfase no sentimento de humanidade poderia indicar uma predisposição a colocá-lo em prática. Não é isso o que ocorre. $\mathrm{O}$ 
artifício continua sendo necessário, pois a justiça deriva de uma reflexão sobre a tendência que temos para agir de acordo com a utilidade pública ${ }^{27}$. Aliás, é essa reflexão sobre as vantagens proporcionadas pela vida em sociedade "que tem um controle mais completo sobre nossos sentimentos" (EPM, III, II, p. 98). Em um dos apêndices, Hume repete o Tratado, quando disserta sobre a naturalidade da justiça, dizendo que o entendimento é natural ao homem, e que em "um animal tão sagaz, aquilo que surge necessariamente do exercício de suas faculdades intelectuais pode com justiça ser considerado natural" (EPM, Apêndice III, p. 173). Portanto, o papel da razão tem relevante importância para trazer à tona nossa humanidade. Acredito que é possível dizer que Hume substitui o "interesse próprio enlightened" do Tratado, entendido aqui como a coincidência entre interesse próprio e público, na medida em que o primeiro proporciona o segundo, pelo "sentimento de humanidade enlightened" da segunda Investigação, que, apesar de ser desinteressado, é também artificial, dependendo, portanto, do entendimento para cumprir seu papel. O primeiro era modificado pelo entendimento, enquanto o segundo é apenas realçado ou reavivado por ele.

É interessante notar que esse mesmo problema continua sendo discutido, o que demonstra sua atualidade. Amartya Sen, em seu Desenvolvimento como liberdade, ao comentar a expressão "escolha racional" e o conceito de simpatia em Adam Smith, diz que é importante distinguir entre simpatia e comprometimento. ${ }^{28}$ Diz que no caso da simpatia, nosso auto-interesse leva em conta a consideração por outras pessoas, em uma noção mais ampla de bemestar do indíviduo. Já o compromentimento vai além, pois é uma disposição para "fazer sacrifícios para promover outros valores, como justiça social, nacionalismo ou bem-estar da comunidade":

Se você ajuda uma pessoa miserável porque essa miséria faz com que você se sinta infeliz, essa terá sido uma ação baseada na simpatia. Mas se a presença da pessoa miserável não o deixa particularmente infeliz, porém faz com que você se sinta absolutamente decidido a mudar um sistema que considera injusto (ou, de um modo mais geral, se sua resolução não é totalmente explicável pela infelicidade criada pela presença daquela pessoa miserável), então essa seria uma ação baseada no comprometimento (Sen, 2002, p. 307).

Assim, o Hume do Tratado aproxima-se, ao tratar da justiça e de seus motivos, da descrição de simpatia feita por Sen, enquanto que o Hume da 
segunda Investigação aproxima-se da descrição de comprometimento. Porém, a "escolha racional" de que trata Sen é bem diferente da de Hume. Vejamos um pouco mais sobre o papel do entendimento no que chamei de sentimento de humanidade enlightened, para vermos porque a virtude da justiça continua sendo artificial.

Como já sabíamos desde o Tratado, apesar de afirmações como a de que a "razão é escrava das paixões", ou de que "a moralidade é mais propriamente sentida do que julgada", Hume não nega ao entendimento um papel relevante. Apenas diz que a razão, sozinha, não é capaz de determinar nossas crenças morais e nossas ações. ${ }^{29}$ Seu papel é o de influenciar nossa conduta quando suscita uma paixão e nos informa da existência de um objeto adequado, ou quando revela uma conexão de causa e efeito para a fixação dos meios para o exercício de determinada paixão. ${ }^{30}$

O que nos move é a paixão. As paixões violentas usualmente são as que mais nos afetam, mas "as paixões calmas, quando confirmadas pela reflexão e apoiadas pela resolução, são capazes de as dominar nos seus momentos mais furiosos" (TNH, II, III, VIII, p. 295). Uma pessoa com maior firmeza de caráter é capaz de dominar esses momentos furiosos com maior frequiência. Assim, o sentimento de humanidade, como paixão calma, está também apto a sobrepor-se ao interesse próprio, usualmente composto de paixões violentas (fome, sede, esperança e medo, amor e ódio, inveja, desejo...), desde que "confirmado pela reflexão e apoiado pela resolução".

Para Rawls, a razão humeana não pode criar ou eliminar paixões inexistentes, mas pode alterar seu grau de influência ou fazer-nos ver que temos uma paixão sobre a qual não nos tenhamos dado conta, o que influencia significativamente nossa conduta. ${ }^{31}$ A resolução é uma virtude construída pelo costume e pelo hábito, pois aprendemos a utilizá-la e, com a prática dessa capacidade, vemos que esse exercício nos dá prazer. Quem tem firmeza de caráter está mais inclinado a agir assim, pois as paixões calmas podem exercer um controle maior sobre nós. De qualquer modo, as pessoas, em diferentes graus, com a prática da resolução, têm prazer em fazê-lo e exercitam sua crescente capacidade de fazer prevalecer as paixões calmas sobre as violentas.

Desse modo, o sentimento de humanidade enlightened é o "confirmado pela reflexão e apoiado pela resolução", que pode controlar nossas paixões mais interessadas e violentas. É esse o artifício que permite a prevalência das 
regras de justiça e a existência da vida social. O artifício da justiça, assim, deixa de ser algo predominantemente interessado (interesse imediato ou de longo prazo), ou seja, uma meia-virtude, para transformar-se em uma virtude inteira.

\section{A justiça humeana e o artifício contratualista}

Acredito que os argumentos anteriormente expostos, sobre a construção do artifício da justiça em Hume, representem uma maneira incomum de contrapor-se ao artifício criado pelos contratualistas, e não menos eficiente.

Dois são os principais pontos de divergência entre as teorias humeana e as contratualistas em geral, no que se refere ao artifício: o papel da razão na formação do pacto e, sobretudo, o processo da construção do artifício, ambos interligados. Em Hume, como visto, a razão ajuda a fazermos com que nossas paixões mais calmas, como o sentimento de humanidade, prevaleçam e guiem nossas ações. O processo pelo qual a construção do artifício tem lugar é o da prática social, do uso reiterado da razão, apenas para determinar o grau de influência de nossas paixões.

Já no caso do artifício elaborado pelos contratualistas, a razão realiza desejos, sejam os derivados do medo da morte no estado de guerra de todos contra todos (Hobbes), sejam os existentes em uma situação menos periclitante, não beligerante, mas em que não deixa de haver uma inquietude que nos moveria na busca de maior conforto e estabilidade, proporcionados pelo contrato (Locke). Quanto ao processo de elaboração, o artifício dos contratualistas não decorre da prática ou da evolução social, mas, como diz Forbes, do arbítrio. ${ }^{32} \mathrm{O}$ pacto surge de um cálculo interessado, o que o Hume da segunda Investigação, nos termos anteriormente expostos, nega mais claramente. Essa é a maneira pela qual acredito que uma interpretação desprendida daquela que podemos considerar a interpretação padrão, ou oficial, pode propiciar uma maneira singular de refutação do contratualismo, não mencionada pelos comentaristas de Hume.

Para Hobbes, a lei de natureza, que tem caráter obrigacional e contrapõese ao direito de natureza, que por sua vez representa a liberdade reinante no estado de natureza, é criação eminentemente racional, não consensual e nem socialmente construída: 
Portanto, a verdadeira razão é uma lei certa, que (já que faz parte da natureza humana, tanto quanto qualquer outra faculdade ou afecção da mente) também é denominada natural. Por conseguinte, assim defino a lei de natureza: é o ditame da reta razão no tocante àquelas coisas que, na medida de nossas capacidades, devemos fazer, ou omitir, a fim de assegurar a conservação da vida e das partes de nosso corpo (Do Cid., I, II, § $1^{\circ}$, p. 38). ${ }^{33}$

O próprio Hume, na segunda Investigação, situa Hobbes entre aqueles que pensam ser nossas paixões sempre interessadas, mesmo as mais beneficentes. Assim, o interesse próprio enlightened, que propiciava o artifício no Tratado, guardadas as devidas diferenças, tem finalidade similar à da razão arbitrária de Hobbes, isto é, definir o artifício como um cálculo interessado, embora para o primeiro esse cálculo decorra de uma prática social que influencia nossas paixões, enquanto que para o segundo decorra da prevalência da razão:

Um epicurista ou hobbesiano admitirá prontamente que existe no mundo a amizade, sem hipocrisia ou disfarce, embora possa tentar, por uma química filosófica, reduzir os elementos dessa paixão, por assim dizer, aos da outra, e explicar todas as afecções como sendo o amor a si mesmo distorcido e moldado, por um viés particular da imaginação, em uma diversidade de aparências (EPM, Apêndice II, p. 165).

Para Locke, a lei de natureza é a própria razão, que nos foi dada por Deus $^{34}$ (assim como em Hobbes). O pacto decorre dela, e a instituição de um governo faz parte da convenção não porque vivemos em uma situação de guerra, mas porque é melhor abrir mão da justiça privada e atribuí-la a um magistrado único. Também aqui o artifício não precisa de uma prática social, pois a razão antecipa-se a ela e pretensamente resolve o problema, o que, da mesma forma, conflita com a teoria humeana:

(As virtudes) são artificiais porque são criações humanas. Ao mesmo tempo, Hume deixou de lado a simples explicação racionalista dessas instituições como expressões da vontade. Em sua explicação, propriedade e contrato devem existir como práticas sociais antes de qualquer ato de vontade relativos a elas (Haakonsen, 1993, p. 188).

Enfim, para Hume, o entusiasmo contratualista é arbitrário porque é carregado de exaltação e presunção, dando ao homem mais poder do que de fato tem. Assim, como em Hume não temos essas potencialidades, é necessária a explicação de um mecanismo de produção de uma vontade social, decorrente de uma prática prévia, o que não se dá em Hobbes e Locke. Além disso, e 
o que é mais importante, a redução do artifício a um cálculo interessado é contrariada por Hume, segundo a interpretação ora sugerida, que acredito possa ser incluída entre os argumentos humeanos de refutação ao entusiasmo contratualista.

\section{Referências Bibliográficas}

ARAÚJO, Cícero Romão R. Hume on virtues and rights. Manuscrito, Campinas, v. 19, n. 2, p. 145-164, out. 1996.

BAILEI, James. Routledge philosophy guidebook to Hume on morality. London: Routledge, 2000.

FORBES, Duncan. Hume's philosophical politics. Cambridge: Cambridge University Press, 1975.

HAAKONSEN, Knud. The structure of Hume's political theory. In: NORTON, D. F. (Ed.). The Cambridge compagnion to Hume. Cambridge: Cambridge University Press, 1993.

HOBBES, Thomas. Leviathan, or the matter, forme and power of a commonwealth eclesiastical and civil. New York: Oxford, 1996.

Fontes, 1988.

. Do Cidadão. 2. ed. Tradução de Renato Janine Ribeiro. São Paulo: Martins

HUME, David. A treatise of human nature. Oxford: Oxford University Press, 2002.

Press, 1998. . An enquiry concerning the principles of morals. Oxford: Oxford University

. An enquiry concerning human understanding. Oxford: Oxford University Press, 1999.

. Ensaios morais, políticos e literários. Tradução de João Paulo Gomes Monteiro, Sara Albieri e Pedro Galvão. Lisboa: Imprensa Nacional/Casa da Moeda, 2002. KEMP, J. Ethical naturalism: Hobbes and Hume. New York: St. Martin's Press, 1970.

LOCKE, John. Segundo tratado sobre o governo civil. Tradução de Magda Lopes e Marisa Lobo da Costa. Rio de Janeiro: Vozes, 1994.

. Dois tratados sobre o governo. São Paulo: Martins Fontes, 2005.

MACKIE, J. L. Hume's moral theory. London: Routledge, 1995.

MONTEIRO, João Paulo. Teoria, retórica, ideologia. São Paulo: Ática, 1975. . Novos estudos humeanos. São Paulo: Discurso, 2003.

RAWLS, John. A theory of justice. Oxford: Oxford University Press, 1999.

. Lectures on the history of moral philosophy. Cambridge: Harvard University Press, 2000.

SEN, Amartya. Desenvolvimento como liberdade. Tradução de Laura Teixeira Motta.

São Paulo: Companhia das Letras, 2002.

STROUD, Barry. Hume. London: Routledge, 1995. 